\title{
Seasonal dynamics alter taxonomical and functional microbial profiles in Pampa biome soils under natural grasslands
}

\author{
Anthony Diego Muller Barboza ${ }^{1}$, Victor Satler Pylro ${ }^{2}$, Rodrigo Josemar Seminot Jacques ${ }^{3}$ ， Paulo Ivonir \\ Gubiani $^{3}$, Fernando Luiz Ferreira de Quadros ${ }^{4}$, Júlio Kuhn da Trindade ${ }^{5}$, Eric W Triplett ${ }^{6}$, Luiz Roesch ${ }^{\text {Corresp. }}$ \\ 1 1Centro Interdisciplinar de Pesquisas em Biotecnologia - CIP-Biotec, Universidade Federal do Pampa, São Gabriel, Brazil \\ 2 Department of Soil Science, "Luiz de Queiroz" College of Agriculture, University of São Paulo - ESALQ/USP, Piracicaba, Brazil \\ 3 Departamento de Solos, Programa de Pós-graduação em Ciência do Solo, Universidade Federal de Santa Maria, Santa Maria, Brazil \\ 4 Department of Animal Science, Universidade Federal de Santa Maria, Santa Maria, Rio Grande do Sul, Brazil \\ 5 Departamento de Diagnóstico e Pesquisa Agropecuária, Secretaria Estadual da Agricultura, Pecuária e Irrigação, São Gabriel, Brazil \\ 6 Department of Microbiology and Cell Science, University of Florida, Gainesville, United States \\ ${ }^{7}$ Centro Interdisciplinar de Pesquisas em Biotecnologia, Universidade Federal do Pampa, São Gabriel, Brazil
}

Corresponding Author: Luiz Roesch

Email address: luizroesch@unipampa.edu.br

Soil microbial communities' assembly is strongly tied to changes in temperature and moisture. Although microbial functional redundancy seems to overcome taxonomical composition changes, the sensitivity and resilience of soil microbial communities from subtropical regions in response to seasonal variations are still poorly understood. Thus, the development of new strategies for biodiversity conservation and sustainable management require a complete understanding of the soil abiotic process involved in the selection of microbial taxa and functions. In this work, we used state of the art molecular methodologies (Next Generation Sequencing) to compare the taxonomic (metataxonomics) and functional (metatranscriptomics) profiles among soil samples from two subtropical natural grasslands located in the Pampa biome, Brazil, in response to short-term seasonal variations. Our data suggest that grasslands maintained a stable microbial community membership along the year with oscillation in abundance. Apparently soil microbial taxa are more susceptible to natural climatic disturbances while functions are more stable and change with less intensity along the year. Finally, our data allow us to conclude that the most abundant microbial groups and functions were shared between seasons and locations reflecting the existence of a stable taxonomical and functional core microbiota. 
1 Seasonal dynamics alter taxonomical and functional microbial profiles in Pampa

biome soils under natural grasslands

4 Anthony Diego Muller Barboza1, Victor Satler Pylro², Rodrigo Josemar Seminoti

5 Jacques $^{3}$, Paulo Ivonir Gubiani ${ }^{3}$, Fernando Luiz Ferreira de Quadros ${ }^{4}$, Júlio Kuhn da

6 Trindade $^{5}$, Eric W. Triplett ${ }^{6}$, Luiz Fernando Wurdig Roesch ${ }^{1 *}$

7

8 'Centro Interdisciplinar de Pesquisas em Biotecnologia - CIP-Biotec, Universidade Federal do Pampa,

9 Campus São Gabriel, Avenida Antonio Trilha, 1847, 97300-000, São Gabriel, Brazil

10 2Department of Soil Science, "Luiz de Queiroz" College of Agriculture, University of São Paulo 11 ESALQ/USP, Piracicaba, SP, Brazil.

12 'Departamento de Solos, Programa de Pós-graduação em Ciência do Solo, Universidade Federal de 13 Santa Maria, Roraima, 1000, 97105-900, Santa Maria, Brazil

14 4Department of Animal Science, Federal University of Santa Maria, Roraima Avenue, 1000, 97105-900, 15 Santa Maria, Brazil.

16 5Departamento de Diagnóstico e Pesquisa Agropecuária, Secretaria Estadual da Agricultura, Pecuária e 17 Irrigação, BR290 KM412, 97300-000, São Gabriel, RS, Brazil.

$18{ }^{6}$ Microbiology and Cell Science Department, Institute of Food and Agricultural Sciences, University of 19 Florida, Gainesville, FL 32611-0700, USA.

20

$21{ }^{*}$ To whom correspondence should be addressed at: Universidade Federal do Pampa, Campus

22 São Gabriel, Avenida Antônio Trilha, 1847, São Gabriel, Rio Grande do Sul, Brazil, 97300-000.

23 E-mail: luizroesch@unipampa.edu.br 


\section{Abstract}

26

27

28

29
Soil microbial communities' assembly is strongly tied to changes in temperature and moisture. Although microbial functional redundancy seems to overcome taxonomical composition changes, the sensitivity and resilience of soil microbial communities from subtropical regions in response to seasonal variations are still poorly understood. Thus, the development of new strategies for biodiversity conservation and sustainable management require a complete understanding of the soil abiotic process involved in the selection of microbial taxa and functions. In this work, we used state of the art molecular methodologies (Next Generation Sequencing) to compare the taxonomic (metataxonomics) and functional (metatranscriptomics) profiles among soil samples from two subtropical natural grasslands located in the Pampa biome, Brazil, in response to short-term seasonal variations. Our data suggest that grasslands maintained a stable microbial community membership along the year with oscillation in abundance. Apparently soil microbial taxa are more susceptible to natural climatic disturbances while functions are more stable and change with less intensity along the year. Finally, our data allow us to conclude that the most abundant microbial groups and functions were shared between seasons and locations reflecting the existence of a stable taxonomical and functional core microbiota. 


\section{1. Introduction}

48 The selection imposed by abiotic environmental factors is an important event

49

50

52

53

54

55

56 57 Firestone, 2006).

58

59

60 contributing to microbial community assembly (Stegen et al., 2012). Although soil microbial communities appeared to be well adapted to some environmental variability (e.g. increase of $4{ }^{\circ} \mathrm{C}$ in soil temperatures) (Schindlbacher et al., 2011), short-term seasonal changes are strongly correlated with shifts in microbial community composition (Wallenstein and Hall, 2012). Diversity and/or abundance of microbial taxa changed between seasons in alpine ecosystems, (Lipson and Schmidt, 2004), temperate grassland ecosystem (Habekost et al., 2008), soils of a temperate beech forest (Rasche et al., 2011) and soils under Mediterranean climate (Waldrop and

Among the deterministic processes governing the composition of microbial communities, environmental factors such as soil $\mathrm{pH}$, temperature and moisture are considered to be main drivers of microbial community assembly (Castro et al., 2010; Fierer and Jackson, 2006; Kaiser et al., 2016; Lauber et al., 2013). Particularly, differences in beta diversity among soils are significantly correlated with soil pH (Lauber et al., 2009). In a large sampling study including 150 forest and 150 grassland soils Kaiser et al., (2016) found soil $\mathrm{pH}$ as the best predictor for bacterial community structure, diversity and function. Under normal rainfall conditions the increase in temperature positively affects the abundance of some soil microbial groups (Sheik et al., 2011). Conversely, increasing temperature was positively correlated with microbial respiration in soil and $\mathrm{CO}_{2}$ production (Luo et al., 2001), which in turn can reduce the population of Actinobacteria sensitive to high $\mathrm{CO}_{2}$ concentrations, for example (Sheik et 
70 al., 2011). Water saturation can drastically alters soil microbial composition, community 71 diversity and function by altering $\mathrm{O}_{2}$ availability (Carbone et al., 2011). On the other

72 hand, drought conditions may benefit organisms adapted to arid conditions (Bouskill et 73 al., 2013).

In subtropical regions, soil temperature and moisture vary strongly during the seasons, influencing microbial community assembly. However, previous work suggests that soil functioning is not affected by the decline of the microbial diversity (Griffiths et al., 2001; Wertz et al., 2007, 2006), and these ecosystems seems to rely on functional redundancy (Frossard et al., 2012; Lupatini et al., 2013; Nannipieri et al., 2003; Rousk et al., 2009).

Although microbial composition changes are not necessarily correlated with soil microbial functions, the sensitivity and resilience of soil microbial communities from subtropical regions in response to seasonal variations are still unclear. Obtaining a better insight into the soil ecological process involved in the selection of microbial taxa and function is paramount for developing new strategies for biodiversity conservation and sustainable management. Moreover, if microbial taxa shift along the year and functions do not change, such information is relevant for planning sampling strategies and for comparing the results from different experiments. Here, we compared taxonomic and functional microbial profiles of soils under subtropical natural grassland from two sites in the Pampa biome, during the warm (summer and autumn) and cold (winter and spring) seasons. The major aim of this study was to test whether short-term seasonal variations (mainly temperature and precipitation), typical in subtropical regions, can 92 cause changes in microbial phylotypes and/or microbial functions. We expected 
93 microbial community abundance and diversity patterns to change due seasonal

94 variation, that is, to increase over the warm season, but microbial functioning to remain

95 stable over seasons.

96

\section{2. Material and Methods}

\subsection{Study Sites}

The study was conducted during 2014 and 2015 in two sites under similar 100 environmental conditions located in the Brazilian Pampa biome: Santa Maria municipality - SM $\left(29^{\circ} 45^{\prime} \mathrm{S}, 53^{\circ} 45^{\prime} \mathrm{W}\right)$ and São Gabriel municipality - SG $\left(30^{\circ} 20^{\prime}\right.$ S, $\left.54^{\circ} 15^{\prime} \mathrm{W}\right), 83 \mathrm{~km}$ far from each other. The sites were chosen because of their similarities in soil features, vegetation, land use, and climate. Soil samples were collected under natural grassland, currently used for grazing of cattle, with no historic of fertilizers input (except for the manure added by animal activity). The sites exhibited similar soil physicochemical characteristics (Table S1) and were classified within the same soil taxonomy.

The sites chosen are exposed to large seasonal variations in soil moisture and 109 temperature (Fig. 1). For this study, the seasons were characterized as warm season

110 (October, November, December, January, February and March) and cold season (April,

111 May, June, July, August and September), due to the similarities in temperature and 112 rainfall between spring and summer as well as autumn and winter. The average air 113 temperatures in the cold season were $16.2^{\circ} \mathrm{C} \pm 2.4$ and $17.5 \pm 2.7^{\circ} \mathrm{C}$ in SM and SG, 114 respectively. In the warm season the average air temperatures were $24.0 \pm 2.8^{\circ} \mathrm{C}$ in $115 \mathrm{SM}$ and $24.1 \pm 1.4^{\circ} \mathrm{C}$ in SG. The monthly average rainfall in the cold season was 107 
$116 \mathrm{~mm}$ in SM and $112 \mathrm{~mm}$ in SG. In the warm season, monthly average rainfall was 154

$117 \mathrm{~mm}$ and $171 \mathrm{~mm}$, in SM and SG, respectively (Fig. 1).

118 The plant species comprising $95 \%$ of the total biomass in SM were: Adropogon

119 lateralis, Aristida laevis, Elephantopus mollis, Bacharis trimera, Paspalum plicatulum

120 and Paspalum notatum, and in SG were: Andropogon lateralis, Axonopus affinis,

121 Baccharis trimera, Eragrostis plana (invasive), Erianthus angustifolius, Paspalum

122 notatum, Paspalum dilatatum, Paspalum plicatulum, Sporobolus indicus and Vernonia 123 nudiflora.

2.2. Soil sampling, nucleic acids extraction and preprocessing

At each grassland (SM and SG), the sampling area was divided in three blocks, and five soil cores per block were randomly selected and pooled to make a single composite sample, resulting in three samples per site at each season [n $=24$, that is, 2 sites (SM and SG), 4 months (May and August, 2014 - cold season / November 2014 and February 2015 - warm season) and 3 replicates per sampling]. Samples were collected with a sterile spatula to a depth of $5 \mathrm{~cm}$, kept in sterile $50 \mathrm{~mL}$ tubes in liquid nitrogen, and then stored at $-80^{\circ} \mathrm{C}$ until DNA and RNA co-extraction. for simultaneous extraction of total RNA and DNA using the RNA PowerSoil kit and the PowerSoil ${ }^{\circledR}$ DNA Elution Accessory Kit (MoBio laboratories, Inc., Carlsbad, CA, USA),

137 following the manufacturer's instructions. After RNA extraction, each sample was 138 subjected to enzymatic digestion of DNA with TURBO DNA-free Kit (Applied 139 Biosystems, Foster City, CA, USA). All RNA and DNA samples were submitted to 
140 quantification and quality-check using a Qubit RNA or DNA assay kit (Invitrogen,

141 Eugene, OR, USA) and NanoVue ${ }^{\mathrm{TM}}$ spectrophotometer (GE healthcare, Chicago, CA

142 USA), respectively, and further stored at $-80^{\circ} \mathrm{C}$ until library preparation.

\subsection{Metatranscriptome library preparation and sequencing}

One microgram of total RNA from each bulk soil sample were depleted by 146 removing rRNA from total RNA with the MICROBExpress ${ }^{\mathrm{TM}}$ Bacterial mRNA Enrichment 147 Kit (Thermo Fisher, Waltham, MA, USA) following the manufacturer's instructions. The 148 mRNA was further purified with the MEGAclear ${ }^{\text {TM }}$ Transcription Clean-Up Kit (Thermo 149 Fisher, Waltham, MA, USA) following the manufacturer's instructions. The enriched 150 mRNA was used to prepare the mRNA library with the lon Total RNA-Seq Kit v2 and lon 151 Xpress $^{\mathrm{TM}}$ RNA-Seq Barcode Kit (Thermo Fisher, Waltham, MA, USA). The libraries 152 were amplified by emulsion PCR and sequenced on lon $316^{\mathrm{TM}}$ Chip v2 using the lon 153 Torrent PGM system and the lon PGM ${ }^{\mathrm{TM}}$ Sequencing 400 kit, according to the supplier's 154 instructions. After sequencing, all reads were filtered by the PGM software to remove 155 low quality and polyclonal sequences.

\subsection{S library preparation and sequencing}

Library preparation and sequencing followed the procedures described by 159 (Suleiman et al., 2016). For analyzing the composition of soil bacterial and archaeal communities the total microbial DNA was used as template for partial 165 rDNA amplification and sequencing. The V4 region of the 16S rRNA gene was amplified using using the PGM lon Torrent (Thermo Fisher Scientific, Waltham, MA, USA). Multiple 
164 samples were PCR-amplified using barcoded primers. Each of the $25 \mu \mathrm{L}$ of PCR

165 mixture consisted of $2 \mathrm{U}$ of Platinum ${ }^{\circledR}$ Taq DNA High Fidelity Polymerase (Invitrogen,

166 Carlsbad, CA, USA), $4 \mu \mathrm{L}$ 10X High Fidelity PCR Buffer, $2 \mathrm{mM} \mathrm{MgSO}, 0.2 \mathrm{mM}$

167 dNTP's, $0.1 \mu \mathrm{M}$ of both the $806 \mathrm{R}$ barcoded primer and the $515 \mathrm{~F}$ primer, and 168 approximately $100 \mathrm{ng}$ of DNA template. The PCR conditions used were $95^{\circ} \mathrm{C}$ for $5 \mathrm{~min}$, 16930 cycles of $94^{\circ} \mathrm{C}$ per $45 \mathrm{~s}$ denaturation; $56^{\circ} \mathrm{C}$ per $45 \mathrm{~s}$ annealing and $72^{\circ} \mathrm{C}$ per 1 min 170 extension; followed by $72^{\circ} \mathrm{C}$ per $10 \mathrm{~min}$. The resulting PCR products were purified with 171 the Agencourt $\circledast$ AMPure $®$ XP Reagent (Beckman Coulter, Brea, CA, USA) and the final 172 concentration of the PCR product was quantified by using the Qubit Fluorometer kit 173 (Invitrogen, Carlsbad, CA, USA) following the manufacturer's recommendations. Finally, 174 the reactions were combined in equimolar concentrations to create a mixture composed 175 by $16 S$ rRNA gene amplified fragments of each sample. This composite sample was 176 used for library preparation with Ion OneTouch ${ }^{\mathrm{TM}} 2$ System with the Ion PGM ${ }^{\mathrm{TM}}$ 177 Template OT2 400 Kit Template (Thermo Fisher Scientific, Waltham, MA, USA). The 178 sequencing was performed using lon $\mathrm{PGM}^{\mathrm{TM}}$ Sequencing 400 on lon $\mathrm{PGM}^{\mathrm{TM}}$ System 179 using lon $316^{\mathrm{TM}}$ Chip v2.

180

\subsection{Bioinformatics analysis and statistics}

The annotation of metatranscriptome sequences was performed with the Metagenomics Rapid Annotation (MG-RAST) pipeline version 3.3.6 (Meyer et al., 2008),

184 using the standard parameters for sequence quality control. The data was compared to 185 the SEED Subsystem using a maximum e-value of $1^{-5}$, a minimum identity of $60 \%$, and 186 a minimum alignment length of 15 measured in aa for protein and bp for RNA 187 databases. The $16 \mathrm{~S}$ rRNA raw sequences were analyzed following the 
188 recommendations of the Brazilian Microbiome Project (Pylro et al., 2014), using the 189 BMP Operating System (BMPOS) (Pylro et al., 2016).

Analysis of Metagenomic Profiles v2 (STAMP) software package was used to 191 determine differences in relative abundances of microbial functions and taxa (Parks et 192 al., 2014). Statistical hypothesis tests were performed using the Welch's $t$ test while 193 confidence intervals were calculated using the Welch's inverted method and Bonferroni 194 multiple test for $p$-value correction. The mRNA and the 16S rRNA datasets were 195 rarefied to the same number of sequences per database (Lemos et al., 2011) and used 196 to construct dissimilarity matrixes generated by Bray Curtis and Binary distances using 197 the "phyloseq" package in R. The matrixes were ordinate by Principal Coordinate Analysis (PCOA) and adonis function was used to calculate the Permutational Multivariate Analysis of Variance (PERMANOVA) and verify the strength and statistical significance of groups among location, season and the combined effect of location and season with the vegan package (Oksanen J et al., 2015). Sampling effort was estimated 202 using Good's coverage (Good, 1953).

Raw sequences obtained by metatranscriptome sequencing and associated 204 metadata were submitted to MG-RAST server (http://metagenomics.anl.gov/) and are public available under the string mgp12046. All raw sequences obtained by amplicon 206 sequencing were submitted to NCBI Sequence Read Archive (SRA) and are available under the experiment number SRX2779549 run number SRR5499445.

\section{Results}


212 After quality filtering the $16 \mathrm{~S}$ rRNA reads, a total of $1,630,136$ high-quality 213 sequences longer than $200 \mathrm{bp}$ were retained. The average Good's coverage of $98 \%$ 214 was calculated (Table S2), indicating the dataset was representative of the microbial 215 communities analyzed. The soil metatranscriptome sequencing yielded a total of $21620,584,533$ reads for all 24 samples, and the average Good's coverage was $77 \%$ (Table 217 S2).

To evaluate the differences in microbial community structure and function 219 between the two natural grasslands and along different seasons, the abundances of 220 microbial taxa and mRNA encoding functions were used to compute a Bray-Curtis 221 dissimilarity matrix coordinated by using PCoA. A Binary similarity matrix was also used 222 to compute differences of either presence/absence of taxa or mRNA encoding 223 functions. Contrasting patterns of microbial taxonomic structure and functions were 224 observed. Although the sites were similar, these analyses revealed differences in 225 microbial taxonomic structure between the two natural grasslands (SM and SG) and 226 between seasons (Fig. 2). Four distinctive groups were observed taking into account the 227 microbial taxonomic structure meaning the soil microbial phylotypes shifted along the 228 year according to the season. When the abundance of mRNA encoding microbial 229 functions was compared, two distinctive groups were observed, representing the cold 230 and the warm seasons. Those results indicate that microbial functions are more resilient 231 to environmental changes than the microbial taxonomic structure. No significant 232 differences in microbial taxonomic structure or microbial functions were observed within 233 the same season in either location. The location did not influence the main functions 234 performed by the microbial communities (Fig. 2). Microbial community differences were 
235 further confirmed by PERMANOVA (Table 1). Season was the main driver of shifts of 236 abundance of taxa and mRNA encoding functions of the soil microbiota. This factor 237 contributed $22 \%$ and $23 \%$ for the variation in microbial taxa and mRNA encoding 238 functions, respectively (Table 1 ). Altogether, these results indicated that soil microbial 239 community structure was affected by location (e.g. two natural grasslands from the same biome, but $83 \mathrm{~km}$ apart) and by the natural environmental changes throughout the year (seasons). Also, location and season interaction was significant at $5 \%$ probability 242 meaning the impact of one factor depends on the level of the other factor or, in other 243 words that microbial community shifts emerge from the interaction location and seasons. On the other hand, the functions performed by soil microbes in those two sampling sites were similar, not being affected by location, but by seasons.

\subsection{Identification of taxa and functions that shifted along seasons and locations}

Once overall taxonomic and functional differences were identified, the functional differences as measured through RNAseq, and taxonomical differences as measured by $16 \mathrm{~S}$ rRNA sequencing, were determined. The seasonal frequency of most abundant microbial phylotypes (relative frequency greater than 1\%) in both locations was determined (Table 2). The data indicated the grassland ecosystem maintained a core microbiota along the year but the relative abundance of taxa varied in response to seasons. As the amount of rain was well distributed along the year (Fig 1), soil moisture was not considered an important variable shaping microbial community assembly in our experiment. Temperature shifted during the year with an average minimum of $10^{\circ} \mathrm{C}$ and an average maximum of $27{ }^{\circ} \mathrm{C}$, representing an important source of environmental 
258 variation influencing microbial life in our experiment. During the warm season, the 259 uncultured member of Verrucomicrobia designated DA101 was the most abundant 260 phylotype in both locations. Mycobacterium and Rhodoplanes were also found in both 261 grasslands with similar high abundances, but better adapted to cold conditions (Table 262 2).

263 In agreement with the differential abundance analysis, alpha diversity 264 measurements indicated similar microbial richness (number of observed OTUs) during 265 the seasons, but greater microbial diversity (Simpson diversity index) during the cold 266 season (Fig. 3). Cold temperatures allowed for greater evenness while warm 267 temperatures decrease the diversity of taxa. The diversity of microbial functions 268 presented similar trends (high diversity during the warm season and low diversity during 269 the cold season), displaying a core set of microbial functions along the year in both 270 locations (Fig. 3 and Table 3). Main functional differences between seasons were 271 consistently detected within both grasslands. Despite the difficulties of defining the 272 functions codified by complex mixtures of mRNA in metatranscriptome library, the 273 metabolism of carbohydrates was the dominant set of functions performed during the 274 cold season in both grasslands. An average of $10.5 \%$ of mRNA with known annotated 275 function was committed to carbohydrate degradation and utilization in the model 276 bacterium Thermotoga maritima, during the cold season in the grassland located in SG. 277 Nevertheless, only $1.1 \%$ of the mRNA sequences were related with this function in the 278 warm season (Table 3). The same pattern was observed in the grassland located in SM $279(7.1 \%$ of mRNA sequences committed to sugar utilization during the cold season and 280 only $0.9 \%$ during the warm season). D-ribose utilization and deoxyribose and 
281 deoxynucleoside catabolism were also functions highly expressed during the cold 282 season in both grasslands. During the warm season functions were more evenly 283 distributed, without dominance of specific ones. The most abundant set of functions 284 during the warm season were those dedicated to the protein metabolism, composing $2855.7 \%$ of mRNA dataset in the grassland located in SG, and $3.5 \%$ in the SM grassland. 286 The functions related to Cofactors, Vitamins, Prosthetic Groups and Pigments were also 287 higher expressed during the warm season in both grasslands.

288

289

290

\section{Discussion}

291

This study aimed to understand how and to what extent seasonal dynamics 292 influence taxonomical and functional microbial profiles in subtropical natural grassland 293 soils, based on metataxonomics (16S rRNA gene) and metatranscriptomics (mRNA) in294 depth sequencing (as defined by Marchesi and Ravel, 2015). We addressed two 295 important variables; season and location, aiming to better understand how these shifting 296 environmental conditions influence microbial community assembly and function in subtropical grasslands from south Brazil. The Brazilian Pampa occupies $2 \%$ of the Brazilian territory and is considered one of the most fragile biomes in the country, 299 experiencing losses of both biodiversity and socio-economic opportunities (Roesch et al., 2009). Natural grasslands are the predominant vegetal cover of this biome, although

301 the climatic conditions are also suitable for forest development, which reflects its 302 biological uniqueness. The soils in both sampling areas (SM and SG) were classified as

303 Paleodult and the vegetal composition was similar but not identical. Our sampling 304 strategy allowed us to obtain a highly tractable model (confounding variables like soil 
305 type and plant cover were controlled), with true landscape level of biological 306 replications, for verifying whether soil microbial functions follow the changes in the 307 abundance of taxa during seasonal variations. Our study revealed consistent effects of 308 season on both microbial community structure and functions, with the former presenting 309 less stability than the latter along the seasons.

310 Season and location significantly modulate microbial community assemblage and 311 abundance in subtropical natural grasslands (Fig. 2). However, considering only those 312 microbes with relative abundance greater than $1 \%$, our data suggest that both 313 grasslands maintained a stable microbial community membership along the time, but 314 the relative abundance of specific taxa oscillated in response to seasonal changes 315 (Table 2). Hence, these results support the existence of a soil core microbiota in natural 316 grasslands that might represent the first step in defining a 'healthy' community and 317 predicting community responses to perturbation (Shade and Handelsman, 2012). The 318 concept of core microbiota was first introduced during the studies of the Human 319 Microbiome Project (Turnbaugh et al., 2007). While the concept of microbial core 320 remain elusive and might lack a conceptual framework involving microbial ecological 321 characteristics (Shade and Handelsman, 2012), typical approaches report the 322 presence/absence of microbial phylotypes across habitats. In the Pampa biome, 323 Lupatini et al. (2013) already found a core microbiota among soil samples under Acacia 324 plantation, natural pasture, soybean field, and natural forest. Within this study, $54.5 \%$ of 325 OTUs (defined by 16 S rRNA sequences with $97 \%$ similarity) were shared among four 326 different land uses. Similarly, (Suleiman et al., 2013) found a total of $69 \%$ of the OTUs 327 shared between a natural grassland and a pristine forest in the Brazilian Pampa biome. 
328 In our study, with the same land use, the presence of a soil microbial core exists in

329 which the most abundant bacterial groups were shared between different seasons and 330 locations.

331 While a group of microbes were found to be able to survive throughout the year, 332 relevant shifts in abundance of those groups along the seasons were apparent. These 333 changes might be explained by nutrient fluxes caused by carbohydrates inputs 334 (monosaccharides like glucose and fructose, oligosaccharides like maltose and sucrose 335 and polysaccharides like cellulose and pectin) from senescent plants. Plant biomass 336 production is low or even zero during the winter due to the climatic conditions that affect 337 the most abundant plant species from natural grasslands. In south Brazil, the cold 338 season covers around one third to half of the year. Low temperatures and frosts 339 decrease the plant growth and plant senescence is intensified causing most of the 340 forage to be rejected by the animals during the grazing. The entire process exacerbates 341 the accumulation of litter and carbohydrates in soil. Under such conditions the 342 availability of abundant and different carbon sources might be responsible for the 343 changes observed in our experiment. Bacteria have access to greater availability of 344 rhizodepositions in the summer but in the winter, when the rhizodeposition is very 345 reduced, the easily decomposable carbon sources are very scarce in soil.

346 Cold conditions decreased the abundance of some taxa below the detection limit 347 provided by our sequencing coverage. The apparent decrease in diversity during the 348 warm season (Fig. 3) might be interpreted as an effect of increasing the abundance of 349 fast growing microorganisms - e.g. greater abundance of DA101 during the warm 350 season (Table 2), rather than the loss of microbial species. The concept that observed 
351 changes in community composition are actually variations in the relative abundance of

352 taxa rather than extinction and recolonization of taxa in the ecosystem was previously

353 raised by Caporaso et al., (2012) in a study of seasonal dynamics in microbial

354 community composition of the Western English Channel. Here, most microbial taxa are

355 always present in these soils but vary in abundance with shifts in seasons. To validate

356 this hypothesis a deeper sequence survey should be performed within our samples in

357 order to obtain a better picture of the rare biosphere (Lynch and Neufeld, 2015).

358 Despite the similar number of observed species found between seasons,

359 samples collected during the warm season were more heterogeneous and presented

360 greater variability than those collected in the cold season (Fig. 3). Cold temperatures

361 allowed for greater evenness while warm temperatures caused an apparent decrease in

362 diversity. In the cold temperatures, a more even abundance distribution allows more

363 taxa to be sampled when the same number of sequences is examined, causing the

364 richness to appear higher. Temperature variation restricts survival of a few species or

365 genera sensitive to a specific temperature condition (Li et al., 2015), which corroborate

366 the aforementioned statement. As the amount of rain was well distributed along the year

367 (Fig. 1), the temperature was considered the main source of environmental variation for

368 microbial life in our experiment.

369 Temperature may directly affect microbial metabolism, by restricting the activity

370 of those microbes unable to thrive at low temperatures. Temperature can also indirectly

371 affect microbial communities by reducing plant growth, thereby decreasing carbon

372 rhizodeposition (Murphy et al., 2016). Most plant species of subtropical grasslands are

373 perennial but present lower growth rate and higher senescence rate during the winter. 
374 Thus, rhizodeposition of available carbon sources is reduced during the winter which in

375 turn affects fast growing microbial populations. Furthermore, fast-growing microbial

376 populations might be adapted to easily degradable materials during the winter due to

377 the plant litter decomposition while slow-growing microorganisms are favored when

378 substrate availability is limiting (Rui et al., 2009). Thus, regardless of the environmental

379 conditions (warm or cold), the different soil niches will be likely to be occupied by some

380 member of the microbial community. The level of environmental constraints imposed by

381 the subtropical region on bacterial communities is significant, encouraging functional

382 redundancy and resilience to be further explored.

383 Although the soil, vegetation cover, temperature, and rainfall regime are similar in

384 the Pampa biome and the sampling areas were relatively close to each other, the soil

385 microbial community structure was also affected by location (Fig. 2). These differences

386 are related to the inherently high level of spatial heterogeneity observed in soil (Lauber

387 et al., 2013). While we attempted to sample areas as homogeneous as possible, and

388 besides the similarity between soils from the two areas, the natural variation between

389 soils resulted in differences between soils of $77 \%, 26 \%, 73 \%, 67 \%, 108 \%$ and $133 \%$ in

390 the contents of $\mathrm{Al}, \mathrm{P}, \mathrm{Ca}, \mathrm{Mg}, \mathrm{Zn}$ e B, respectively. Besides, as mentioned above,

391 vegetation cover was similar but no identical. The species Aristida laevis and

392 Elephantopus mollis were detected only in SM while the plant species Axonopus affinis,

393 Eragrostis plana Erianthus angustifolius, Paspalum dilatatum, Sporobolus indicus and

394 Vernonia nudiflora were only detected in SG. Finally, the presence of the highly invasive

395 and allelopathic plant, Eragrostis plana, can alter important ecological components of

396 microhabitats (Guido et al., 2016). Therefore, these differences in soil and vegetation 
397 may result in different abiotic conditions between the two sites, capable of altering the 398 composition and activity of the soil microbial community.

399

400

401

402

403

404

405

406

407

408

409

410

411 412 taxonomical and functional core microbiota.

413

414

415

416

417

418

419

420

\section{Conclusions}

\section{Acknowledgements} experimental area for sampling in São Gabriel.

Here we reported the effects of seasons and location on soil microbial taxonomy and functional profiles providing insights in the ecological rules shaping soil microbial communities and their functions in natural ecosystems. Season and location significantly modulate microbial community assemblage and abundance in subtropical natural grasslands. However, our data suggest that grasslands maintained a stable microbial community membership along the year with oscillation in abundance. Apparently soil microbial taxa are more susceptible to natural climatic disturbances while functions are more stable and change with less intensity along the year. Finally, our data allow us to conclude that the most abundant microbial groups and functions were shared between seasons and locations reflecting the existence of a stable

The authors acknowledge Dra. Manoeli Lupatini for taking soil samples from the Santa Maria site. We also like to thank the Fundação Estadual a Pesquisa Agropecuária do Estado do Rio Grande do Sul (FEPAGRO) for providing the 


\section{References}

422

423

424

425

426

427

428

429

430

431

432

433

434

435

436

437

438

439

440

441

442

443

444

445

446

447

448

449

450

451

452

453

454

455

456

457

458

459

460

461

462

463

464

465

466

467

468

469

470

Aanderud, Z.T., Jones, S.E., Fierer, N., Lennon, J.T., 2015. Resuscitation of the rare biosphere contributes to pulses of ecosystem activity. Front. Microbiol. 6. https://doi.org/10.3389/fmicb.2015.00024

Bouskill, N.J., Lim, H.C., Borglin, S., Salve, R., Wood, T.E., Silver, W.L., Brodie, E.L., 2013. Preexposure to drought increases the resistance of tropical forest soil bacterial communities to extended drought. ISME J. 7, 384-394. https://doi.org/10.1038/ismej.2012.113

Caporaso, J. G., Lauber, C.L., Walters, W.A., Berg-Lyons, D., Huntley, J., Fierer, N., Owens, S.M., Betley, J., Fraser, L., Bauer, M., Gormley, N., Gilbert, J.A., Smith, G., Knight, R., 2012. Ultrahigh-throughput microbial community analysis on the Illumina HiSeq and MiSeq platforms. ISME J 6, 1621-4. https://doi.org/10.1038/ismej.2012.8

Caporaso, J. Gregory, Paszkiewicz, K., Field, D., Knight, R., Gilbert, J.A., 2012. The Western English Channel contains a persistent microbial seed bank. ISME J. 6, 1089-1093. https://doi.org/10.1038/ismej.2011.162

Carbone, M.S., Still, C.J., Ambrose, A.R., Dawson, T.E., Williams, A.P., Boot, C.M., Schaeffer, S.M., Schimel, J.P., 2011. Seasonal and episodic moisture controls on plant and microbial contributions to soil respiration. Oecologia 167, 265-278. https://doi.org/10.1007/s00442-011-1975-3

Castro, H.F., Classen, A.T., Austin, E.E., Norby, R.J., Schadt, C.W., 2010. Soil Microbial Community Responses to Multiple Experimental Climate Change Drivers. Appl. Environ. Microbiol. 76, 9991007. https://doi.org/10.1128/AEM.02874-09

Fierer, N., Jackson, R.B., 2006. The diversity and biogeography of soil bacterial communities. Proc. Natl. Acad. Sci. 103, 626-631. https://doi.org/10.1073/pnas.0507535103

Frossard, A., Gerull, L., Mutz, M., Gessner, M.O., 2012. Disconnect of microbial structure and function: enzyme activities and bacterial communities in nascent stream corridors. ISME J. 6, 680-691.

Good, I.J., 1953. The population frequencies of species and the estimation of population parameters. Biometrika 40, 237-264.

Griffiths, B.., Ritz, K., Wheatley, R., Kuan, H.., Boag, B., Christensen, S., Ekelund, F., Sørensen, S.., Muller, S., Bloem, J., 2001. An examination of the biodiversity-ecosystem function relationship in arable soil microbial communities. Soil Biol. Biochem. 33, 1713-1722. https://doi.org/10.1016/S0038-0717(01)00094-3

Guido, A., Vélez-Martin, E., Overbeck, G.E., Pillar, V.D., 2016. Landscape structure and climate affect plant invasion in subtropical grasslands. Appl. Veg. Sci. 19, 600-610. https://doi.org/10.1111/avsc.12263

Habekost, M., Eisenhauer, N., Scheu, S., Steinbeiss, S., Weigelt, A., Gleixner, G., 2008. Seasonal changes in the soil microbial community in a grassland plant diversity gradient four years after establishment. Soil Biol. Biochem. 40, 2588-2595. https://doi.org/10.1016/j.soilbio.2008.06.019

Kaiser, K., Wemheuer, B., Korolkow, V., Wemheuer, F., Nacke, H., Schöning, I., Schrumpf, M., Daniel, R., 2016. Driving forces of soil bacterial community structure, diversity, and function in temperate grasslands and forests. Sci. Rep. 6. https://doi.org/10.1038/srep33696

Lauber, C.L., Hamady, M., Knight, R., Fierer, N., 2009. Pyrosequencing-Based Assessment of Soil pH as a Predictor of Soil Bacterial Community Structure at the Continental Scale. Appl. Environ. Microbiol. 75, 5111-5120. https://doi.org/10.1128/AEM.00335-09

Lauber, C.L., Ramirez, K.S., Aanderud, Z., Lennon, J., Fierer, N., 2013. Temporal variability in soil microbial communities across land-use types. ISME J 7, 1641-1650.

Lemos, L.N., Fulthorpe, R.R., Triplett, E.W., Roesch, L.F.W., 2011. Rethinking microbial diversity analysis in the high throughput sequencing era. J. Microbiol. Methods 86, 42-51. https://doi.org/10.1016/j.mimet.2011.03.014

Li, H., Yang, Q., Li, J., Gao, H., Li, P., Zhou, H., 2015. The impact of temperature on microbial diversity and AOA activity in the Tengchong Geothermal Field, China. Sci. Rep. 5. https://doi.org/10.1038/srep17056 
471

472

473

474

475

476

477

478

479

480

481

482

483

484

485

486

487

488

489

490

491

492

493

494

495

496

497

498

499

500

501

502

503

504

505

506

507

508

509

510

511

512

513

514

515

516

517

518

519

520

Lipson, D.A., Schmidt, S.K., 2004. Seasonal Changes in an Alpine Soil Bacterial Community in the Colorado Rocky Mountains. Appl. Environ. Microbiol. 70, 2867-2879. https://doi.org/10.1128/AEM.70.5.2867-2879.2004

Luo, Y., Wan, S., Hui, D., Wallace, L.L., 2001. Acclimatization of soil respiration to warming in a tall grass prairie. Nature 413, 622-625. https://doi.org/10.1038/35098065

Lupatini, M., Suleiman, A.K.A., Jacques, R.J.S., Antoniolli, Z.I., Kuramae, E.E., de Oliveira Camargo, F.A., Roesch, L.F.W., 2013. Soil-Borne Bacterial Structure and Diversity Does Not Reflect Community Activity in Pampa Biome. PLoS ONE 8, e76465. https://doi.org/10.1371/journal.pone.0076465

Lynch, M.D.J., Neufeld, J.D., 2015. Ecology and exploration of the rare biosphere. Nat. Rev. Microbiol. 13, 217-229. https://doi.org/10.1038/nrmicro3400

Marchesi, J.R., Ravel, J., 2015. The vocabulary of microbiome research: a proposal. Microbiome 3. https://doi.org/10.1186/s40168-015-0094-5

Meyer, F., Paarmann, D., D’Souza, M., Olson, R., Glass, E., Kubal, M., Paczian, T., Rodriguez, A., Stevens, R., Wilke, A., Wilkening, J., Edwards, R., 2008. The metagenomics RAST server - a public resource for the automatic phylogenetic and functional analysis of metagenomes. BMC Bioinformatics 9, 386. https://doi.org/10.1186/1471-2105-9-386

Murphy, A.C., Foster, L.B., Gao, C., 2016. Temporal Dynamics in Rhizosphere Bacterial Communities of Three Perennial Grassland Species. Agronomy 6. https://doi.org/10.3390/agronomy6010017

Nannipieri, P., Ascher, J., Ceccherini, M., Landi, L., Pietramellara, G., Renella, G., 2003. Microbial diversity and soil functions. Eur. J. Soil Sci. 54, 655-670.

Oksanen J, Blanchet F G, Kindt R, Legendre P, Minchin P R, O’Hara R B, Simpson G L, Solymos P, Stevens M H H, Wagner H, 2015. Vegan: community ecology package. R package vegan, vers. 2.2-1.

Parks, D.H., Tyson, G.W., Hugenholtz, P., Beiko, R.G., 2014. STAMP: statistical analysis of taxonomic and functional profiles. Bioinformatics 30, 3123-3124. https://doi.org/10.1093/bioinformatics/btu494

Pylro, V.S., Morais, D.K., de Oliveira, F.S., dos Santos, F.G., Lemos, L.N., Oliveira, G., Roesch, L.F., 2016. BMPOS: a flexible and user-friendly tool sets for microbiome studies. Microb. Ecol. 72, 443-447.

Pylro, V.S., Roesch, L.F.W., Morais, D.K., Clark, I.M., Hirsch, P.R., Tótola, M.R., 2014. Data analysis for $16 \mathrm{~S}$ microbial profiling from different benchtop sequencing platforms. J. Microbiol. Methods $107,30-37$.

Rasche, F., Knapp, D., Kaiser, C., Koranda, M., Kitzler, B., Zechmeister-Boltenstern, S., Richter, A., Sessitsch, A., 2011. Seasonality and resource availability control bacterial and archaeal communities in soils of a temperate beech forest. ISME J. 5, 389-402.

Roesch, L.F.W., Vieira, F.C.B., Pereira, V.A., Schünemann, A.L., Teixeira, I.F., Senna, A.J.T., Stefenon, V.M., 2009. The Brazilian Pampa: a fragile biome. Diversity 1, 182-198.

Rousk, J., Brookes, P.C., Baath, E., 2009. Contrasting Soil pH Effects on Fungal and Bacterial Growth Suggest Functional Redundancy in Carbon Mineralization. Appl. Environ. Microbiol. 75, 15891596. https://doi.org/10.1128/AEM.02775-08

Rui, J., Peng, J., Lu, Y., 2009. Succession of Bacterial Populations during Plant Residue Decomposition in Rice Field Soil. Appl. Environ. Microbiol. 75, 4879-4886. https://doi.org/10.1128/AEM.00702-09

Schindlbacher, A., Rodler, A., Kuffner, M., Kitzler, B., Sessitsch, A., Zechmeister-Boltenstern, S., 2011. Experimental warming effects on the microbial community of a temperate mountain forest soil. Soil Biol. Biochem. 43, 1417-1425. https://doi.org/10.1016/j.soilbio.2011.03.005

Shade, A., Handelsman, J., 2012. Beyond the Venn diagram: the hunt for a core microbiome: The hunt for a core microbiome. Environ. Microbiol. 14, 4-12. https://doi.org/10.1111/j.14622920.2011.02585.x 
521

522

523

524

525

526

527

528

529

530

531

532

533

534

535

536

537

538

539

540

541

542

543

544

545

546

547

Sheik, C.S., Beasley, W.H., Elshahed, M.S., Zhou, X., Luo, Y., Krumholz, L.R., 2011. Effect of warming and drought on grassland microbial communities. ISME J. 5, 1692-1700.

Stegen, J.C., Lin, X., Konopka, A.E., Fredrickson, J.K., 2012. Stochastic and deterministic assembly processes in subsurface microbial communities. ISME J 6, 1653-1664.

Suleiman, A.K., Gonzatto, R., Aita, C., Lupatini, M., Jacques, R.J., Kuramae, E.E., Antoniolli, Z.I., Roesch, L.F., 2016. Temporal variability of soil microbial communities after application of dicyandiamide-treated swine slurry and mineral fertilizers. Soil Biol. Biochem. 97, 71-82.

Suleiman, A.K.A., Manoeli, L., Boldo, J.T., Pereira, M.G., Roesch, L.F.W., 2013. Shifts in soil bacterial community after eight years of land-use change. Syst. Appl. Microbiol. 36, 137-144.

Turnbaugh, P.J., Ley, R.E., Hamady, M., Fraser-Liggett, C.M., Knight, R., Gordon, J.I., 2007. The human microbiome project. Nature 449, 804-10. https://doi.org/10.1038/nature06244

Waldrop, M.P., Firestone, M.K., 2006. Seasonal Dynamics of Microbial Community Composition and Function in Oak Canopy and Open Grassland Soils. Microb. Ecol. 52, 470-479. https://doi.org/10.1007/s00248-006-9100-6

Wallenstein, M.D., Hall, E.K., 2012. A trait-based framework for predicting when and where microbial adaptation to climate change will affect ecosystem functioning. Biogeochemistry 109, 35-47. https://doi.org/10.1007/s10533-011-9641-8

Wertz, S., Degrange, V., Prosser, J.I., Poly, F., Commeaux, C., Freitag, T., Guillaumaud, N., Roux, X.L., 2006. Maintenance of soil functioning following erosion of microbial diversity. Environ. Microbiol. 8, 2162-2169. https://doi.org/10.1111/j.1462-2920.2006.01098.x

Wertz, S., Degrange, V., Prosser, J.I., Poly, F., Commeaux, C., Guillaumaud, N., Le Roux, X., 2007. Decline of soil microbial diversity does not influence the resistance and resilience of key soil microbial functional groups following a model disturbance. Environ. Microbiol. 9, 2211-2219. https://doi.org/10.1111/j.1462-2920.2007.01335.x 


\section{Figures and Tables}

549

550 Fig. 1. Seasonal dynamics of temperature and rainfall in two natural grasslands (SG and SM)

551 from the Pampa biome.

552 The asterisks depict the sampling period.

553

554 Fig. 2. Principal coordinates plot (PCoA) representing clusters of soil microbial communities

555 grouped by taxa or functions in two different natural grasslands (SG and SM) and seasons (cold 556 and warm) in the Pampa biome.

557 Ellipses around groups represent 95\% confidence intervals for the standard error of the average

558 scores for each group. (A) Abundance of microbial taxa. (B) Abundance of microbial functions.

559 (C) Presence/Absence of microbial taxa. (D) Presence/Absense of microbial functions.

560

561 Fig. 3. Alpha diversity measurements of microbial taxa and functions during cold and warm 562 seasons in two grasslands from the Pampa biome.

563 Each panel represents one alpha diversity measurement as follow: (A) Total number of OTU's 564 observed. (B) Shannon diversity index calculated for microbial taxa. (C) Simpson diversity index 565 calculated for microbial taxa. (D) Total number of functions observed. (E) Shannon diversity 566 index calculated for microbial functions. (F) Simpson diversity index calculated for microbial 567 functions. Boxes span the first to third quartiles. The horizontal line inside the boxes represents 568 the median. Whiskers extending vertically from the boxes indicate variability outside the upper 569 and lower quartiles, and the single circles indicate outliers. Both datasets were rarefied to the 570 same number of sequences before alpha diversity measurements. (ns) Non significant 571 difference at $p$-value $\leq 0.05$ according to the pairwise t test. $\left(^{*}\right)$ Significant difference at $p$-value $572 \leq 0.05$ according to the pairwise t test. ${ }^{* *}$ ) Significant difference at $p$-value $\leq 0.01$ according to 573 the pairwise $t$ test. 
574

575 Table 1. Multivariate Analysis of Variance showing the differences between soil microbial

576 communities and functions.

577

578 Table 2. Seasonal frequency of major bacterial groups detected in soil samples collected in two 579 natural grasslands during different seasons.

580 * The Welch's t-test was performed to obtain the p-values for the null hypothesis of no difference between

581 warn and cold seasons. Only the genera with abundance greater then $1 \%$ are depicted here.

582

583 Table 3. Relative abundance of mRNA encoding functions during cold and warm seasons in two 584 different grasslands located in the Pampa biome.

585 * The Welch's t-test was performed to obtain the $p$-values for the null hypothesis of no difference between 586 warn and cold seasons. Only the functions with abundance greater than $1 \%$ and with difference between 587 treatments with significant $p$-values $(\leq 0.05)$ are depicted here. Number highlighted in bold represent 588 greater abundance during either cold or warm season. 
Figure 1

Fig. 1. Seasonal dynamics of temperature and rainfall in two natural grasslands (SG and SM) from the Pampa biome.

The asterisks depict the sampling period.

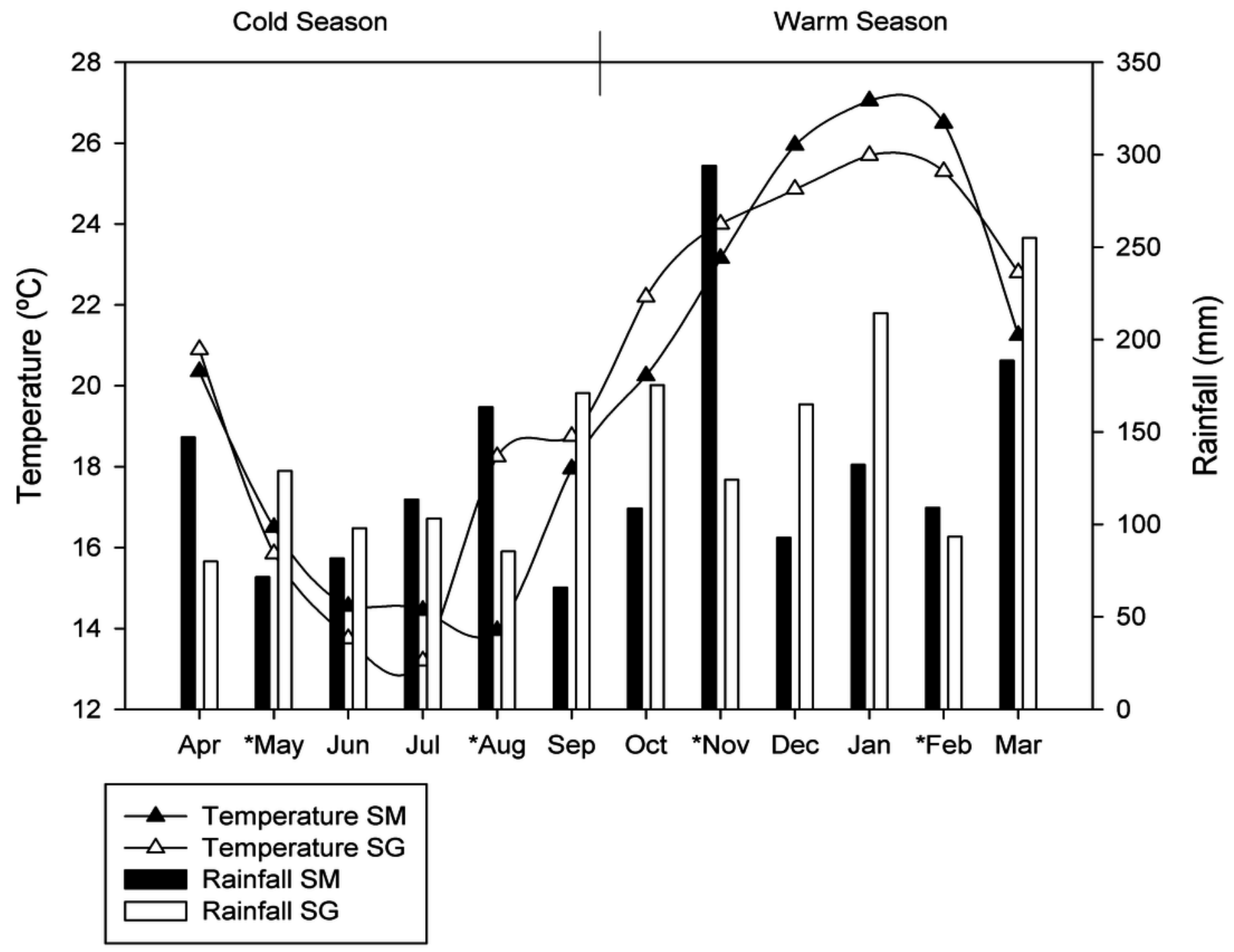




\section{Figure 2}

Principal coordinates plot (PCOA) representing clusters of soil microbial communities grouped by taxa or functions in two different natural grasslands (SG and SM) and seasons (cold and warm) in the Pampa biome.

Ellipses around groups represent $95 \%$ confidence intervals for the standard error of the average scores for each group. (A) Abundance of microbial taxa. (B) Abundance of microbial functions. (C) Presence/Absence of microbial taxa. (D) Presence/Absense of microbial functions. 

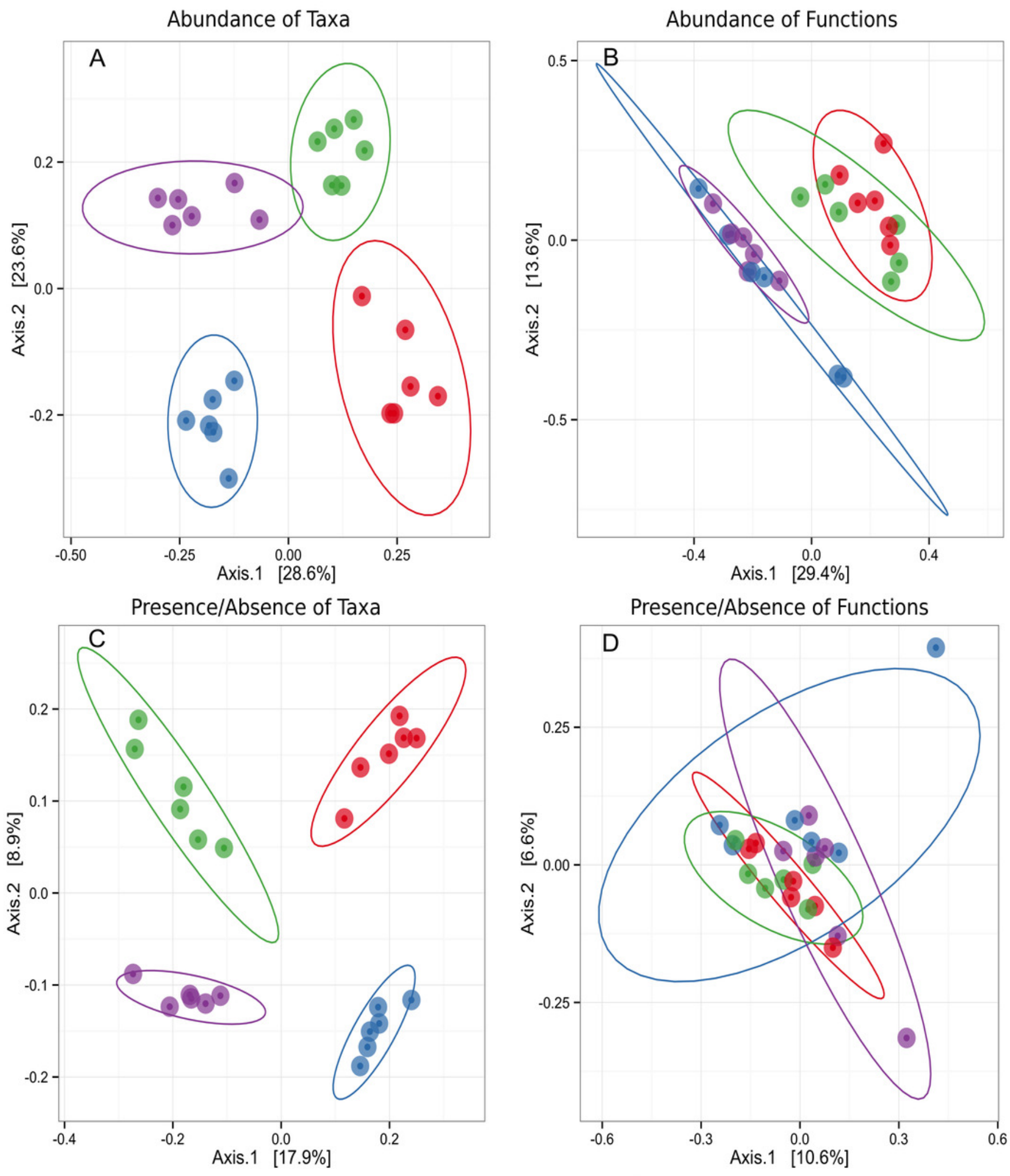

SG cold $\because$ SG warm

SM cold $-S M$ warm 


\section{Figure 3}

Alpha diversity measurements of microbial taxa and functions during cold and warm seasons in two grasslands from the Pampa biome.

Each panel represents one alpha diversity measurement as follow: (A) Total number of OTU's observed. (B) Shannon diversity index calculated for microbial taxa. (C) Simpson diversity index calculated for microbial taxa. (D) Total number of functions observed. (E) Shannon diversity index calculated for microbial functions. (F) Simpson diversity index calculated for microbial functions. Boxes span the first to third quartiles. The horizontal line inside the boxes represents the median. Whiskers extending vertically from the boxes indicate variability outside the upper and lower quartiles, and the single circles indicate outliers. Both datasets were rarefied to the same number of sequences before alpha diversity measurements. (ns) Non significant difference at $p$-value $\leq 0.05$ according to the pairwise $t$ test. $(*)$ Significant difference at $p$-value $\leq 0.05$ according to the pairwise $t$ test. $(* *)$ Significant difference at $\mathrm{p}$-value $\leq 0.01$ according to the pairwise $t$ test. 

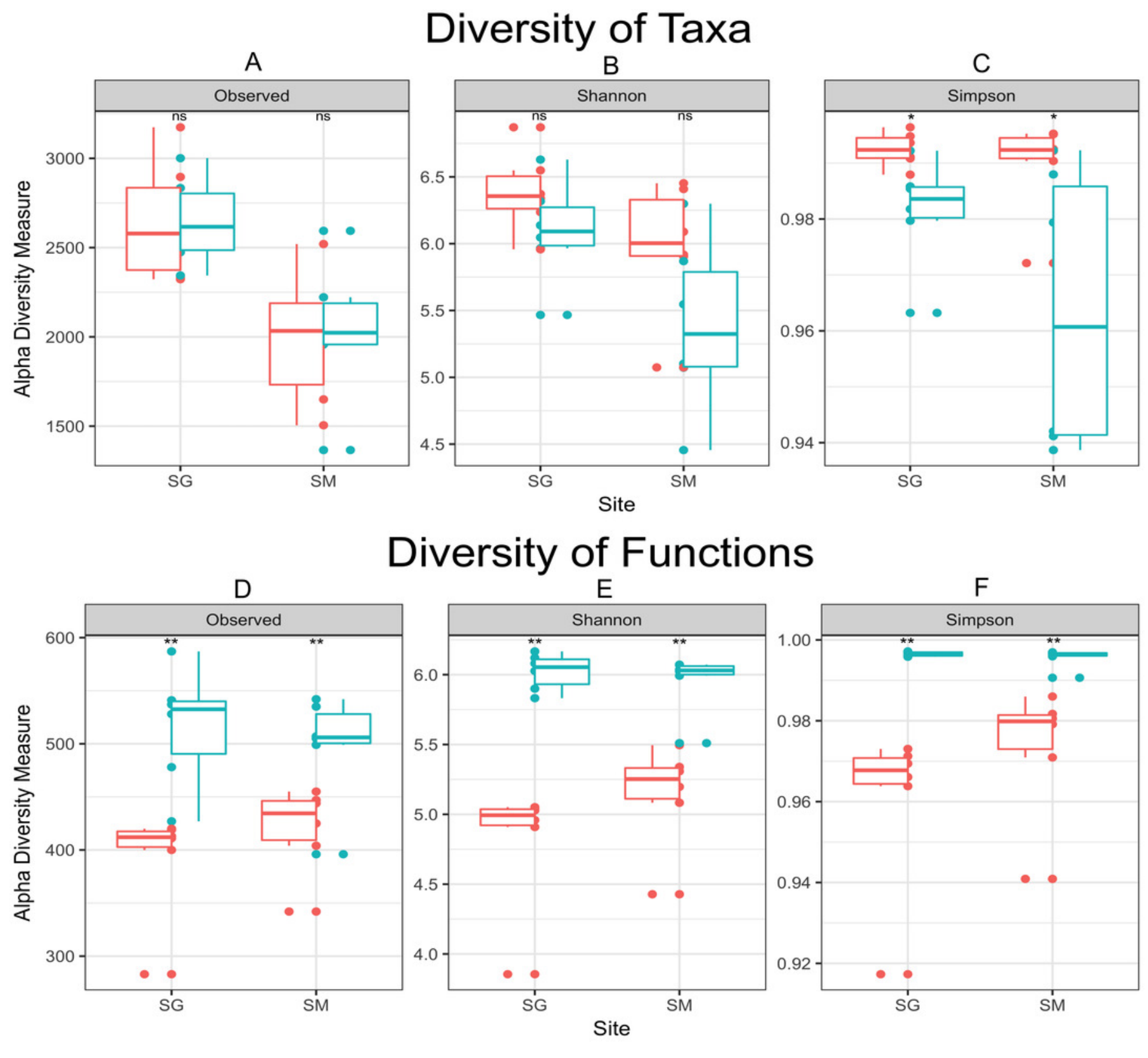

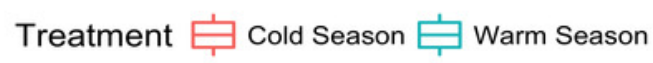




\section{Table $\mathbf{1}$ (on next page)}

Table 1. Multivariate Analysis of Variance showing the differences between soil microbial communities and functions. 
1 Table 1. Multivariate Analysis of Variance showing the differences among soil microbial 2 communities and functions.

3

\begin{tabular}{lcccc}
\hline Factors & \multicolumn{2}{c}{ Abundance of Taxons } & \multicolumn{2}{c}{$\begin{array}{c}\text { Abundance of mRNA encoding } \\
\text { Functions }\end{array}$} \\
\hline \multirow{2}{*}{ Location } & $\mathrm{R}^{2}$ & $p$-value & $\mathrm{R}^{2}$ & $p$-value \\
Season & 0.262 & 0.001 & 0.036 & 0.327 \\
Local x Season & 0.223 & 0.001 & 0.234 & 0.001 \\
& 0.055 & 0.016 & 0.042 & 0.214 \\
\hline & Presence/Absence of Taxons & Presence/Absence of mRNA \\
& \multicolumn{2}{c}{ encoding Functions } \\
\hline \multirow{2}{*}{ Location } & $\mathrm{R}^{2}$ & $p$-value & $\mathrm{R}^{2}$ & $p$-value \\
Season & 0.085 & 0.002 & 0.040 & 0.696 \\
Local x Season & 0.170 & 0.001 & 0.054 & 0.019 \\
\hline
\end{tabular}

4 


\section{Table 2 (on next page)}

Table 2. Seasonal frequency of major bacterial groups detected in soil samples collected in two natural grasslands during different seasons.

* The Welch's t-test was performed to obtain the p-values for the null hypothesis of no difference between warn and cold seasons. Only the genera with abundance greater then $1 \%$ are depicted here. 
1 Table 2. Seasonal frequency of major bacterial groups detected in soil samples

2 collected in two natural grasslands during different seasons.

\begin{tabular}{lccc}
\hline & \multicolumn{2}{c}{ Location SG } \\
& Warm Season & Cold Season & \\
\hline Phylum/genus* & Relative Frequency \pm std. dev. $(\%)$ & $p$-values \\
Acidobacteria/Candidatus Koribacter & $2.25 \pm 0.73$ & $1.20 \pm 0.55$ & 0.0293 \\
Actinobacteria/Mycobacterium & $0.16 \pm 0.04$ & $1.31 \pm 0.60$ & 0.0080 \\
Firmicutes/Bacillus & $0.54 \pm 0.51$ & $2.46 \pm 1.45$ & 0.0301 \\
Proteobacteria/Rhodoplanes & $2.89 \pm 0.37$ & $6.26 \pm 1.05$ & 0.0004 \\
Verrucomicrobia/Candidatus Xiphinematobacter & $0.98 \pm 0.59$ & $3.17 \pm 1.65$ & 0.0298 \\
Verrucomicrobia/DA101 & $23.76 \pm 7.57$ & $7.79 \pm 4.05$ & 0.0035 \\
\hline & & Location SM & \\
& Warm Season & Cold Season & \\
\hline Actinobacteria/Mycobacterium & Relative Frequency \pm std. dev. $(\%)$ & $p$-values \\
Proteobacteria/Rhodoplanes & $0.28 \pm 0.06$ & $1.34 \pm 0.48$ & 0.0040 \\
Verrucomicrobia/DA101 & $1.83 \pm 0.51$ & $5.35 \pm 1.23$ & 0.0007
\end{tabular}

3 * The Welch's t-test was performed to obtain the $\mathrm{p}$-values for the null hypothesis of no difference between

4 warn and cold seasons. Only the genera with abundance greater then $1 \%$ are depicted here. 


\section{Table 3 (on next page)}

Table 3. Relative abundance of mRNA encoding functions during cold and warm seasons in two different grasslands located in the Pampa biome.

* The Welch's t-test was performed to obtain the $p$-values for the null hypothesis of no difference between warn and cold seasons. Only the functions with abundance greater than $1 \%$ and with difference between treatments with significant $p$-values $(\leq 0.05)$ are depicted here. Number highlighted in bold represent greater abundance during either cold or warm season. 
Table 3. Relative abundance of mRNA encoding functions during cold and warm seasons in two different grasslands

2 located in the Pampa biome.

\begin{tabular}{|c|c|c|c|c|}
\hline \multicolumn{3}{|c|}{ SEED subsystems* } & \multicolumn{2}{|c|}{ Location SG } \\
\hline Level 1 & Level 2 & Level 3 & $\begin{array}{l}\text { Cold } \\
\text { Season }\end{array}$ & $\begin{array}{l}\text { Warm } \\
\text { Season }\end{array}$ \\
\hline & & & \multicolumn{2}{|c|}{ Mean rel. freq. $(\%) \pm$ SD } \\
\hline Carbohydrates & Carbohydrates & Sugar utilization in Thermotogales & $10.5 \pm 1.9$ & $1.1 \pm 0.3$ \\
\hline Carbohydrates & Monosaccharides & D-ribose utilization & $10.0 \pm 2.0$ & $0.4 \pm 0.1$ \\
\hline Carbohydrates & Monosaccharides & $\begin{array}{l}\text { Deoxyribose and Deoxynucleoside } \\
\text { Catabolism }\end{array}$ & $10.0 \pm 2.0$ & $0.4 \pm 0.1$ \\
\hline RNA Metabolism & RNA Metabolism & Group II intron-associated genes & $7.0 \pm 2.5$ & $2.0 \pm 0.7$ \\
\hline Protein Metabolism & Protein degradation & Proteolysis in bacteria, ATP-dependent & $1.2 \pm 0.3$ & $2.4 \pm 0.5$ \\
\hline Carbohydrates & One-carbon Metabolism & Serine-glyoxylate cycle & $1.0 \pm 0.3$ & $1.4 \pm 0.3$ \\
\hline Protein Metabolism & Protein biosynthesis & Universal GTPases & $0.9 \pm 0.2$ & $1.4 \pm 0.2$ \\
\hline $\begin{array}{l}\text { Cofactors, Vitamins, Prosthetic } \\
\text { Groups, Pigments }\end{array}$ & Folate and pterines & YgfZ & $0.8 \pm 0.1$ & $1.2 \pm 0.2$ \\
\hline Motility and Chemotaxis & Flagellar motility in Prokaryota & Flagellum & $0.5 \pm 0.1$ & $0.7 \pm 0.1$ \\
\hline Protein Metabolism & Protein degradation & Proteasome bacterial & $0.5 \pm 0.1$ & $0.8 \pm 0.2$ \\
\hline RNA Metabolism & Transcription & Transcription initiation, bacterial sigma factors & $0.5 \pm 0.1$ & $1.0 \pm 0.1$ \\
\hline \multirow[t]{2}{*}{ Protein Metabolism } & Protein folding & Protein chaperones & $0.5 \pm 0.2$ & $1.1 \pm 0.4$ \\
\hline & & & \multicolumn{2}{|c|}{ Location SM } \\
\hline Carbohydrates & Carbohydrates & Sugar utilization in Thermotogales & $7.1 \pm 1.0$ & $0.9 \pm 0.2$ \\
\hline Carbohydrates & Monosaccharides & $\begin{array}{l}\text { Deoxyribose and Deoxynucleoside } \\
\text { Catabolism }\end{array}$ & $6.4 \pm 0.9$ & $0.2 \pm 0.1$ \\
\hline Carbohydrates & Monosaccharides & D-ribose utilization & $6.4 \pm 0.9$ & $0.3 \pm 0.1$ \\
\hline Protein Metabolism & Protein degradation & Proteolysis in bacteria, ATP-dependent & $1.4 \pm 0.4$ & $2.3 \pm 0.5$ \\
\hline Carbohydrates & One-carbon Metabolism & Serine-glyoxylate cycle & $1.2 \pm 0.1$ & $1.5 \pm 0.1$ \\
\hline $\begin{array}{l}\text { Cofactors, Vitamins, Prosthetic } \\
\text { Groups, Pigments }\end{array}$ & Folate and pterines & YgfZ & $0.9 \pm 0.2$ & $1.4 \pm 0.2$ \\
\hline Protein Metabolism & Protein biosynthesis & Universal GTPases & $0.8 \pm 0.2$ & $1.2 \pm 0.2$ \\
\hline
\end{tabular}

* Protein Metabolism

functions with abundance greater than $1 \%$ and with difference between treatments with significant $p$-values $(\leq 0.05)$ are depicted here. Number

highlighted in bold represent greater abundance during either cold or warm season. 